\title{
Regional climate change and local urbanization effects on weather variables in Southeast China
}

\author{
Ji Chen $\cdot$ Qinglan Li $\cdot$ Jun Niu $\cdot$ Liqun Sun
}

Published online: 13 July 2010

(c) The Author(s) 2010. This article is published with open access at Springerlink.com

\begin{abstract}
This paper presents the analyses of regional climate change features and the local urbanization effects on different weather variables over Southeast China. The weather variables considered are: daily mean $\left(\mathrm{T}_{\mathrm{m}}\right)$, minimum $\left(\mathrm{T}_{\min }\right)$, and maximum $\left(\mathrm{T}_{\max }\right)$ near surface air temperature, diurnal temperature range (DTR), relative humidity $(\mathrm{RH})$, and precipitation $(\mathrm{P})$. With analysis of two datasets (a station dataset for the period from 1960 to 2005 that is mainly used and a grid dataset for the period 19602000), this study reveals that the trends in the variations of these weather variables can be separated into two periods, before and after 1984. Before 1984, there were no significant urbanization effects, and $\mathrm{T}_{\min }, \mathrm{RH}$, and $\mathrm{P}$ steadily increased but $\mathrm{T}_{\max }$ decreased, resulting in a considerable decrease in DTR and a slight decrease in $\mathrm{T}_{\mathrm{m}}$. After 1984, $\mathrm{T}_{\min }$ and $\mathrm{T}_{\max }$ increased considerably, and the urbanization influence on $\mathrm{T}_{\text {min }}$, but not $\mathrm{T}_{\max }$, is observable. The urbanization effect causes an extra increasing trend in $\mathrm{T}_{\min }$ with a rate of about $0.6^{\circ} \mathrm{C} /$ decade and, accordingly, extra decreasing trends in DTR and RH. The analysis of the seasonal trends reveals that the urbanization influence results in a near-uniform increase of $\mathrm{T}_{\min }$ for all four seasons and a strong decrease of $\mathrm{RH}$ in summer and autumn. Moreover, there is no significant change in $\mathrm{P}$ at the annual scale and an increasing rate of $11.8 \% /$ decade in summer. With the urbanization influence, a considerable increase in $\mathrm{P}$ is noticeable at the annual scale; specifically, the increasing rates of $18.6 \% /$ decade in summer and $13.5 \% /$ decade in autumn are observed.
\end{abstract}

J. Chen $(\bowtie) \cdot$ Q. Li · J. Niu $\cdot$ L. Sun

Department of Civil Engineering, The University of Hong Kong,

Pokfulam, Hong Kong, China

e-mail: jichen@hkucc.hku.hk
Keywords Climate change - Urbanization effect . Least squares regression . Sen-slope method . Southeast China

\section{Introduction}

In the Fourth Assessment Report (AR4) of the Intergovernmental Panel on Climate Change (IPCC 2007), climate change refers to a change in the state of the climate that can be identified by changes in the mean and/or the variability of its properties. From observations of increases in global average air and ocean temperatures, widespread melting of snow and ice, and rising global average sea level, climate change in the twentieth century is unequivocal (IPCC 2007). Vose et al. (2005) analyzed daily minimum $\left(T_{\min }\right)$ and maximum $\left(\mathrm{T}_{\max }\right)$ temperature trends from 1950 to 2004 for $71 \%$ of the total global land area and revealed that $\mathrm{T}_{\min }$ and $\mathrm{T}_{\max }$ increased in almost all parts of the globe during both periods studied, i.e. 1950-2004 and 19792004, whereas a widespread decrease in the diurnal temperature range (DTR) was only evident from 1950 to 1980. The study by Hansen et al. (2006) showed that the global surface temperature $\left(\mathrm{T}_{\mathrm{m}}\right)$ has increased by about $0.2^{\circ} \mathrm{C} /$ decade in the past 30 years. With the HadCRUH dataset, Willett et al. (2008) reported that the global surface relative humidity $(\mathrm{RH})$ trends are not significant over the land surface although some seasonal changes are significant. Bates et al. (2008) indicated that precipitation (P) has mostly increased over land in high northern latitudes during the 20th century, while decreases have dominated from latitudes $10^{\circ} \mathrm{S}$ to $30^{\circ} \mathrm{N}$ since the $1970 \mathrm{~s}$.

Over China, numerous studies have investigated the climate change phenomenon (e.g. Qian and Zhu 2001; Qian and Lin 2005; Becker et al. 2006; Zhang et al. 2009). Qian and 
Zhu (2001) studied the climate change from 1880 to 1998 and revealed that in Northeast China the aridification trend had become more serious since the 1980s and in South China the highest temperature had appeared for the period 1930s-1940s. Using a daily rainfall dataset for the period 1961-2000, Qian and Lin (2005) identified increasing trends in P intensity in both Northwest China and Southeast China. Becker et al. (2006) showed that the annual P trends were significant and positive in most of the Yangtze River catchment for the past 50 years, while the study by Zhang et al. (2009) reported that increasing summer $P$ was observed in the Pearl River basin for the period 1950-2005.

In the investigation of climate change, it is regarded as one of the major concerns to evaluate anthropogenic influences, especially urbanization, on climate (Kalnay and Cai 2003). Comparing observations for the period from 1951 to 1990 between urban and rural weather stations in Turkey, Tayanç and Toros (1997) found urban warming to be more or less equally distributed over the year with a slight increase in the autumn months. Through analyzing the observational records and reanalysis data over the United States, Kalnay and Cai (2003) reported that over the past 50 years half of the observed decrease in DTR was due to urban and other land-use changes. The main feature of urbanization is the urban heat island (UHI) effect, and the study by Li et al. (2004) suggested that the UHI effect on temperature change was much smaller than the background change in regional temperature from 1951 to 2000 in China. Zhou et al. (2004) found a warming of mean surface temperature of $0.05^{\circ} \mathrm{C} / \mathrm{dec}$ ade attributable to the UHI effect from 1979 to 1998 in Southeast China. For North China, the study by Ren et al. (2008) estimated a positive trend in urban warming at $0.11^{\circ} \mathrm{C} / \mathrm{decade}$ for the period 1960-2000.

Through these studies, and many others, a basic understanding of climate change and the UHI effects has been established (IPCC 2007). However, due to the complex relationships among the different weather variables involved in the study of climate change, information on the relationships among the different weather variables regarding climate change and the urbanization effects is still rather limited. Therefore, a comprehensive study of a range of weather variables may further expand our knowledge of the relationship between climate and urbanization. This paper presents such a study to investigate the climate change characteristics and the influence of urbanization on weather variables in Southeast China.

\section{Study area and data}

The study area covers the region with latitudes ranging from $21^{\circ} \mathrm{N}$ to $25^{\circ} \mathrm{N}$ and longitudes $111^{\circ} \mathrm{E}$ to $116^{\circ} \mathrm{E}$ (see
Fig. 1), and includes the Pearl River Delta (PRD) and the cities of Hong Kong and Macau. In this study, because analysis of station data can provide straightforward information of climate change trends, and, for climate research, gridded weather datasets can be easily used, two datasets are used. One is the homogenized station dataset for the period 1951-2005 ( $\mathrm{Li}$ et al. 2009), and the other is the grid dataset with a resolution of $1^{\circ} \times 1^{\circ}$ from 1951 to 2000 (Feng et al. 2004). Monthly series of six weather variables $\left(\mathrm{T}_{\min }, \mathrm{T}_{\max }, \mathrm{T}_{\mathrm{m}}, \mathrm{DTR}, \mathrm{RH}\right.$, and $\left.\mathrm{P}\right)$ from these two datasets are analyzed.

The quality of both the datasets was checked, using station metadata, logic and consistency check, and homogeneity detection (Feng et al. 2004; Li et al. 2009). The grid dataset developed by Feng et al. (2004) adopted the same numerical scheme that was used to develop the gridded daily temperature and P datasets in the USA (Higgins et al. 1996) and the weather datasets of the US NOAA (National Oceanic and

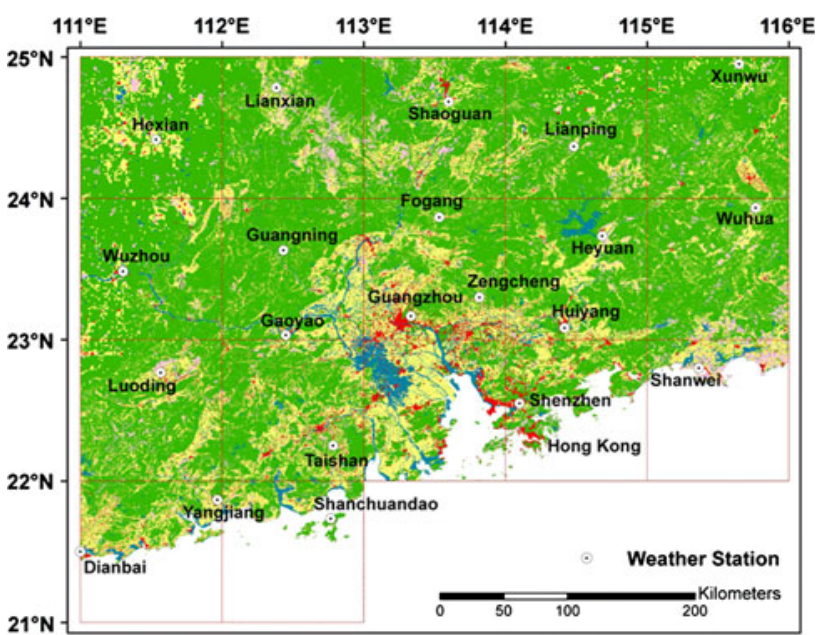

(a)

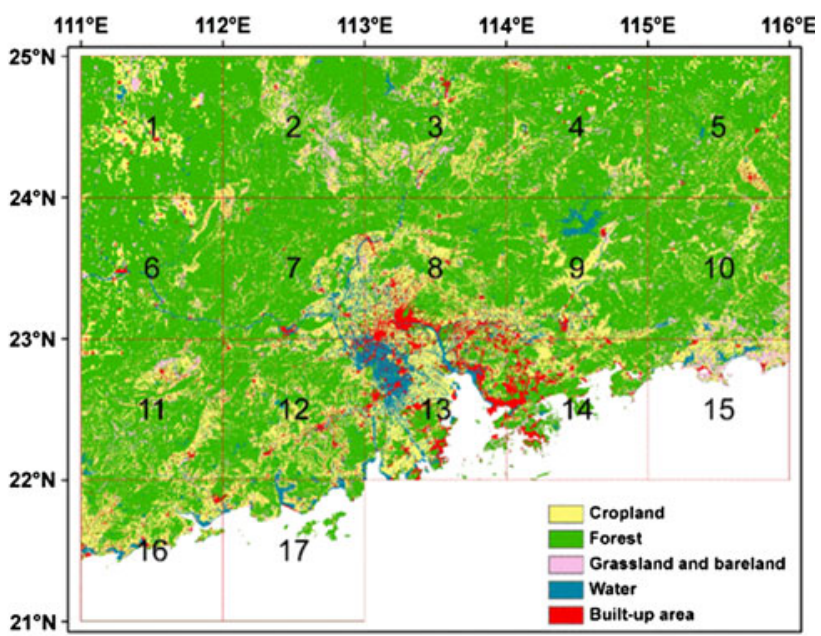

(b)

Fig. 1 Study area and land use in a 1980 and b 2000. a Locations of 21 measuring stations, and b 17 grids with resolution $1^{\circ} \times 1^{\circ}$ 
Atmospheric Administration) Climate Prediction Center. Because the number of missing observations has been reduced and the distribution of the weather station density has been stable since 1960 (Feng et al. 2004; Li et al. 2009), the study period in this paper starts at 1960 instead of 1951.

In the study area, there are 21 weather stations (see Fig. 1a) and $171^{\circ} \times 1^{\circ}$ grids (see Fig. 1b). From Fig. 1a, it can be observed that these 21 stations are rather uniformly distributed in the study area. Among them, Guangzhou is the capital city of Guangdong Province, and Shenzhen the first city in China which adopted the reform and open policy in the late 1970s; both of these cities had a population of more than 6 million in 2005 and have experienced rapid expansion of the built-up area and increase of population since the mid-1980s (Weng 2001). By contrast, the other 19 stations are located in relatively small cities, with a comparatively slow increase of the built-up area and population. Therefore, in this study, the cities of Guangzhou and Shenzhen are regarded as the fast developing cities (denoted as FDC) and the others as the slow developing cities (denoted as SDC). The comparison of the climate trends of these two categories of cities is used to analyze the urbanization influence on climate (see Sects. 4 and 5 for details).

Figure $2 \mathrm{a}$ shows the time series of population and the land cover type of built-up area from 1983 to 2005 for the FDC and SDC areas, collected from a series of Guangdong Yearbooks (e.g. Guangdong Statistic Bureau 2006). The time series for the FDC are the average population and built-up area for the cities of Guangzhou and Shenzhen. The series for SDC are the averages of the available population records from 12 stations, namely Lianxian, Shaoguan, Fogan, Lianping, Guangniang, Gaoyao, Heyuan, Zengcheng, Wuhua, Luoding, Taishan, and Dianbai, and the averages of the available records of built-up area from four stations, namely Shaoguan, Heyuan, Shanwei, and Yangjiang since 1988. From Fig. 2a, it can be observed that the increases in population and built-up area for the FDC and SDC are consistent and comparable.

Figure 1 shows the land cover in 1980 (Fig. 1a) and in 2000 (Fig. 1b) with five land cover categories: cropland, grassland and bare land, forest, water surface, and built-up area. Comparison of the land cover changes from 1980 to 2000 reveals that, except for built-up area along with cropland, there are no considerable changes. Figure $2 b$ shows the percentages of land cover changes for the two categories of built-up area and cropland for the $171^{\circ} \times 1^{\circ}$ grids. They are computed as follows: $100 \% \times$ (land cover area (2000) - land cover area (1980))/land cover area (1980). From Fig. 2b, it is seen that the built-up area of most grids increase along with the decrease of the cropland areas. In addition, the increases in the percentage of built-up area of grids $7,8,13,14$, and 17 are considerable, and the percentages are larger than $50 \%$ in grids 13 and 14 .

\section{Methods}

For detecting climate change trends, the Mann-Kendall (MK) test (e.g. Tayanç and Toros 1997; Becker et al. 2006) is usually used. In addition, due to its simplicity and intuitive aspect, the linear least squares regression method (e.g. Leung et al. 2004; Li et al. 2004; Zhou et al. 2004) is also widely used to detect trends. In this study, the linear least squares regression and MK test are applied to analyze climate change and urbanization effects. According to Hamburg (1970), the linear least squares regression equation is given as:

$\hat{Y}=a+b X$

where $X$ and $\hat{Y}$ are predictor (year in this study) and predictand (a weather variable), respectively. The coefficients $a$ and $b$ are computed as follows:

$a=\bar{y}-b \bar{x}$

$b=\frac{\sum_{i=1}^{n} x_{i} y_{i}-n \bar{x} \bar{y}}{\sum_{i=1}^{n} x_{i}^{2}-n \bar{x}^{2}}$

where $\bar{y}$ and $\bar{x}$ are equal to $\frac{1}{n} \sum_{i=1}^{n} y_{i}$ and $\frac{1}{n} \sum_{i=1}^{n} x_{i}$, respectively; $n$ is the sample size; and $y_{i}$ and $x_{i}$ are the samples of the predictand and predictor, respectively. In this study, $y_{i}$ is the anomaly of a study variable, which is computed by the observed value of the study variable minus the 30-year average of the related observations from 1961 to 1990 . The value of $b$ indicates the trend of the variable $y$. To evaluate a confidence level (CL) from the obtained trend by using linear least squares regression, the correlation coefficient of the linear regression is computed as follows:

$r=\frac{\sum_{i=1}^{n}\left(x_{i}-\bar{x}\right)\left(y_{i}-\bar{y}\right)}{\sqrt{\left(\sum_{i=1}^{n}\left(x_{i}-\bar{x}\right)^{2}\right)\left(\sum_{i=1}^{n}\left(y_{i}-\bar{y}\right)^{2}\right)}}$

The value of $r^{2}$ is also called the sample coefficient of determination, which represents the proportion of total variance in $Y$ that has been explained by Eq. 1. Then, according to Hamburg (1970) and Chen and Kumar (2002), the test statistic, $t$, is defined as:

$t(r, n)=\frac{|r| \sqrt{n-2}}{\sqrt{1-r^{2}}}$

where $t(r, n)$ is the point on the Student's $t$ distribution for the number of degrees of freedom $(n-2)$ and correlation 
Fig. 2 a Comparison of population and built-up area from 1983 to 2005 in the fast developing cities (FDC) and slow developing cities (SDC), and $\mathbf{b}$ the percentage of land cover changes of built-up area and cropland for $171^{\circ} \times 1^{\circ}$ grids

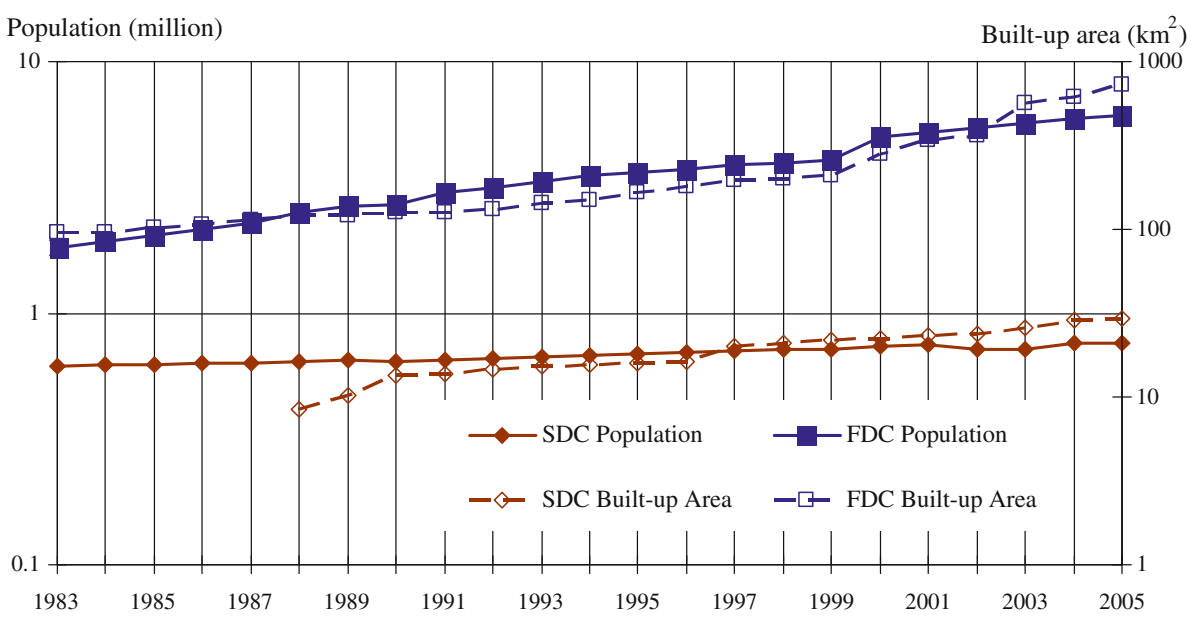

(a)

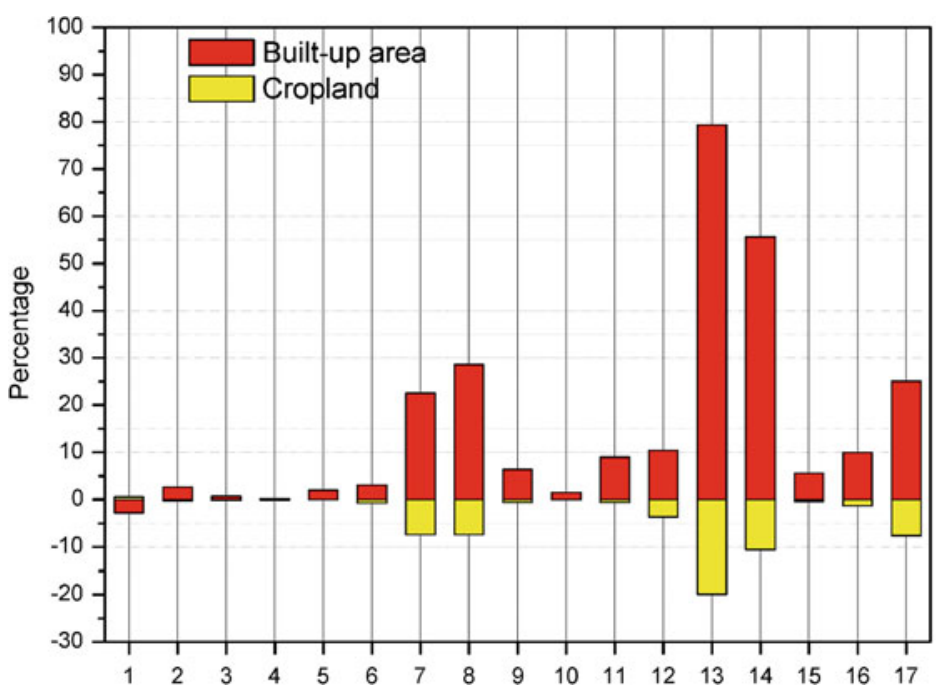

(b) coefficient $r$. Subsequently, the CL $(=1-\alpha)$ is computed as follows:

$1-\alpha=\int_{-t(r, n)}^{t(r, n)} f(t, n) \mathrm{d} t$

where $f(t, n)$ is the probability density function (PDF) of the Student's $t$ test, and $\alpha$ is the significance level of the test.

The other method used in this study is a nonparametric method, the Sen-slope approach (Sen 1968), using the MK statistic test (Mann 1945; Kendall 1975). The nonparametric method is based on the relative ranks of data points, and the slope $b_{i j}$ between each pair of data points $\left(x_{i}, y_{i}\right)$ and $\left(x_{j}, y_{j}\right)$ is computed as follows:

$b_{i j}=\frac{y_{i}-y_{j}}{x_{i}-x_{j}}$

The estimated trend is the median of all the pairwise slopes (Sen 1968). The rank-based nonparametric MK statistic test is then used to assess the significance level, $\alpha$, of the trends of the time series and is calculated as follows (Sen 1968; Gachon et al. 2005):

$\alpha=\frac{\text { concordant }- \text { discordant }}{\sqrt{\text { concordant }+ \text { discordant }+ \text { sameX }} \sqrt{\text { concordant }+ \text { discordant }+ \text { sameY }}}$ 
where concordant is the number of pairs where the relative ordering of $x$ and $y$ are the same, and discordant is the number where they are the opposite. The parameter sameX is the number of pairs where the $x$ values are the same, and the same goes also for sameY. It is worth noting that since $X$ is year in this study same $X$ is 0 .

\section{Temperature change}

\subsection{Annual scale}

The time series of annual anomalous $\mathrm{T}_{\min }, \mathrm{T}_{\max }$, DTR, and $\mathrm{T}_{\mathrm{m}}$ from the 21 stations for the period 1960-2005 are generated and plotted (not shown). From these, it is observed that the variations of $\mathrm{T}_{\min }, \mathrm{T}_{\mathrm{m}}$, and DTR, from the cities of Guangzhou and Shenzhen are considerably different from those from the other 19 cities. Therefore, the observation anomalies from Guangzhou and Shenzhen are combined and averaged to create the anomaly time series for the FDC category, while those from the other 19 cities are combined and averaged to have the anomaly time series for the SDC. Figure 3 shows these anomaly time series; additionally, the global land surface $T_{m}$ (Jones et al. 1999) is plotted in Fig. 3d for comparison.

From the anomaly time series of $\mathrm{T}_{\min }$ in Fig. $3 \mathrm{a}$, it can be observed that the FDC series is noticeably different from the SDC series since 1984. In addition, Fig. 3b shows that the anomaly time series of $\mathrm{T}_{\max }$ has the lowest value in 1984 during the study period, and before and after 1984 the trend is negative and positive (with considerable CLs), respectively. Consequently, in this study, the year 1984 is chosen to denote the starting time of noticeable urbanization effects on climate in the study area and the turning point of climate change over the area; this selection is different from the one (year 1979) chosen by Vose et al. (2005) for the global $T_{\min }$ and $T_{\max }$ trends. Since the present study focuses on Southeast China that has been experiencing high rates of socio-economic development, with accompanying substantial increase of population and built-up area in Guangzhou and Shenzhen since the early 1980s, the selection of the year 1984 seems reasonable. With application of the linear least squares regression method and the Student's $t$ test, the trends, $r^{2}$ values, and

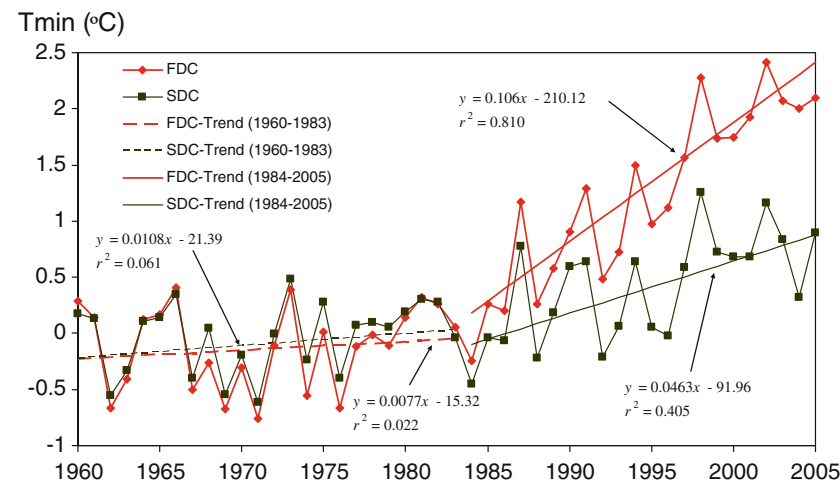

(a)

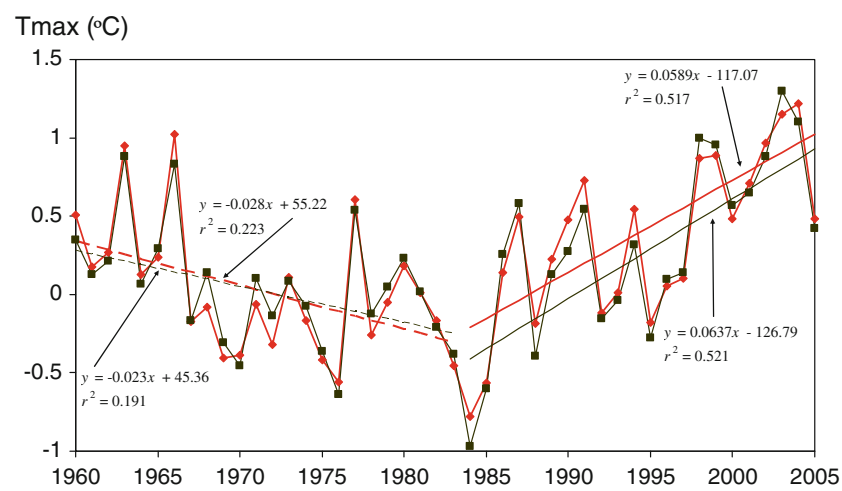

(b)

Fig. 3 Annual time series of the anomalies of $\mathbf{a} \mathrm{T}_{\min }, \mathbf{b} \mathrm{T}_{\max }, \mathbf{c} \mathrm{DTR}$, and $\mathbf{d ~ T}_{\mathrm{m}}$. For the two periods, 1960-1983 and 1984-2005, the linear least squares regression lines and related $r^{2}$ values for these anomalies

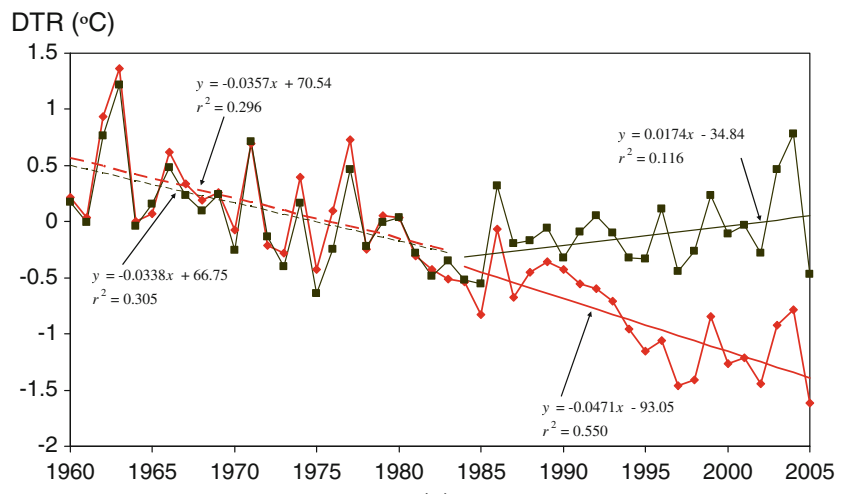

(c)

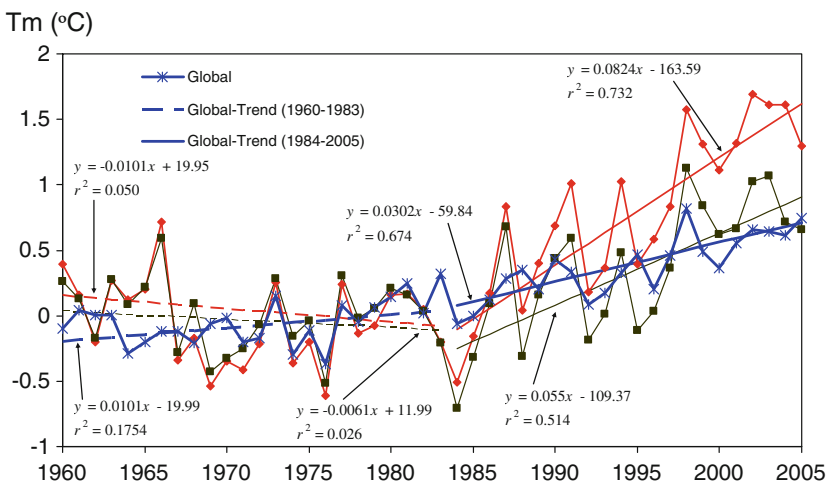

(d)

are presented. The global land surface temperature is included in $\mathbf{d}$ for comparison. The legends are listed in a 
related CLs of the $\mathrm{T}_{\min }, \mathrm{T}_{\max }$, DTR, and $\mathrm{T}_{\mathrm{m}}$ for the FDC and SDC over the two periods, 1960-1983 and 1984-2005, are computed (see Fig. 3).

For pre-1984, the trends of $\mathrm{T}_{\min }, \mathrm{T}_{\max }, \mathrm{DTR}$, and $\mathrm{T}_{\mathrm{m}}$ for the FDC and SDC are rather similar, as can be seen from Fig. 3, which further reveal that the urbanization effects were negligible then. Moreover, Fig. $3 \mathrm{a}$ and $\mathrm{b}$ shows that $\mathrm{T}_{\text {min }}$ changed slightly with an increasing rate of 0.09 $(=10 \times(0.0108+0.077) / 2)^{\circ} \mathrm{C} /$ decade and a small $\mathrm{CL}$ lower than $75 \%$, while, in contrast, $\mathrm{T}_{\max }$ changed considerably with a decreasing rate of $-0.26(=10 \times(-0.028-$ $0.023) / 2)^{\circ} \mathrm{C} /$ decade and a significant CL larger than $95 \%$. The trend features of $\mathrm{T}_{\min }$ and $\mathrm{T}_{\max }$ result in a remarkable decrease of DTR (see Fig. 3c) with a rate of -0.35 $(=-0.26-0.09)^{\circ} \mathrm{C} /$ decade and a significant $\mathrm{CL}$ larger than $99.5 \%$, and slight decrease of $\mathrm{T}_{\mathrm{m}}$ (see Fig. 3d) with a rate of $-0.08^{\circ} \mathrm{C} /$ decade and a small CL lower than $75 \%$. The result of Vose et al. (2005) shows that both of global $\mathrm{T}_{\min }$ and $\mathrm{T}_{\max }$ for the period from 1960 to 1983 increased. In the present study, while the increasing $\mathrm{T}_{\min }$ is consistent with Vose et al. (2005), the decreasing $T_{\max }$ is in contrast to their observations. According to the study by Qian and Zhu (2001), in the 1950s and 1960s, the stronger-than normal southerly wind over South China would have caused severe drought in the region, which might have resulted in the anomalous high $\mathrm{T}_{\max }$ during the period and its decreasing trend from 1960 to 1983. Additionally, Fig. $3 \mathrm{~d}$ shows that the trend of global $\mathrm{T}_{\mathrm{m}}$ increased by $0.10^{\circ} \mathrm{C} /$ decade with a $\mathrm{CL}$ of $96 \%$, which differs appreciably from the observation of $\mathrm{T}_{\mathrm{m}}$ in this study and further exhibits the regional characteristic of climate change.

For post-1984, the urbanization effect on $\mathrm{T}_{\min }$ is significant (see Fig. 3a). The trend of $\mathrm{T}_{\min }$ for the $\mathrm{SDC}$ is $0.46^{\circ} \mathrm{C} /$ decade with a CL of $99.6 \%$, which is larger than the $\mathrm{T}_{\min }$ increase of $0.36^{\circ} \mathrm{C} /$ decade over the Northern Hemisphere for the period 1979-2004 in the study of Vose et al. (2005). Furthermore, the increasing trend of $\mathrm{T}_{\min }$ for the FDC is larger than that for the SDC by $0.60 \quad(=10 \times(0.106-$ $0.0463))^{\circ} \mathrm{C} /$ decade with a CL more than $99.9 \%$, which is about 1.3 times that of the $\mathrm{SDC} \mathrm{T}_{\min }$ trend and would reflect the serious urbanization influence in Southeast China. To the best of our knowledge, no information has been made available in the literature thus far about such a high urbanization effect on $\mathrm{T}_{\min }$ with such a high CL. In contrast to $\mathrm{T}_{\min }$, the difference between the $\mathrm{T}_{\max }$ trends for the FDC and SDC is rather small (see Fig. 3b), and it may be inferred that the urbanization influence on $\mathrm{T}_{\max }$ is negligible. Therefore, the trend of $\mathrm{T}_{\max }$ over the study area is $0.61 \quad(=10 \times$ $(0.0589+0.0637))^{\circ} \mathrm{C} /$ decade with a CL of more than $99.9 \%$, which is more than double the global $\mathrm{T}_{\max }$ trend for the period 1979-2004 obtained by Vose et al. (2005). Since the increasing trend of $\mathrm{T}_{\max }$ is larger than that of $\mathrm{T}_{\min }$ for the SDC, the DTR increased with a CL of $88 \%$, but the DTR for the FDC decreased dramatically with a rate of $-0.47^{\circ} \mathrm{C} /$ decade with a CL of more than $99.9 \%$ (see Fig. 3c). Accordingly, the urbanization effect on $\mathrm{T}_{\mathrm{m}}$ is significant with an increasing rate of $0.27(=10 \times(0.0824-0.055))^{\circ} \mathrm{C} /$ decade (see Fig. 3d) and a CL of more than $99.9 \%$, which is about five times the estimated urbanization effect over the same study area for the period 1979-1998 in the study by Zhou et al. (2004). The increasing trend of $T_{m}$ with a rate of $0.55^{\circ} \mathrm{C} /$ decade for the SDC is also much larger than the global $\mathrm{T}_{\mathrm{m}}$ of $0.30^{\circ} \mathrm{C} /$ decade (see Fig. $3 \mathrm{~d}$ ).

The analysis of the anomaly time series for the 21 stations reveals the features of climate change and the urbanization effect, and such features can be further confirmed by analyzing the grid dataset. Table 1 lists the results of $\mathrm{T}_{\min }, \mathrm{T}_{\max }$, and DTR over these 17 grids for two periods: $1960-1983$ and 1984-2000. The spatial variations of these trends are apparent. Generally, in the first period, $\mathrm{T}_{\min }$ increased, while $\mathrm{T}_{\max }$ and DTR decreased. In the second period, $\mathrm{T}_{\min }$ and $\mathrm{T}_{\max }$ increased, and DTR also increased, except for three grids $(3,13$, and 14). Checking DTR in grid 3, over the second period, the decreasing trend is $-0.04^{\circ} \mathrm{C} /$ decade with a CL lower than $20 \%$, and, in contrast, the decreasing trends over grids 13 and 14 are 0.08 and $-0.14^{\circ} \mathrm{C} /$ decade with CLs of $56 \%$ and $85 \%$, respectively. Therefore, it may be concluded that the urbanization effect over grids 13 and 14 are observable, which is consistent with the built-up area changes presented in Fig. 2b. Furthermore, with the grid dataset, with

Table 1 Trends (in ${ }^{\circ} \mathrm{C} /$ decade) of $\mathrm{T}_{\min }, \mathrm{T}_{\max }$, and DTR in 17 grids for two periods: 1960-1983 (denoted as A) and 1984-2000 (denoted as B)

\begin{tabular}{lllllllr}
\hline Grid & $\mathrm{T}_{\min }$ & & & $\mathrm{T}_{\max }$ & & \multicolumn{2}{l}{$\mathrm{DTR}$} \\
\cline { 2 - 3 } & $\mathrm{A}$ & $\mathrm{B}$ & $\mathrm{A}$ & $\mathrm{B}$ & $\mathrm{A}$ & $\mathrm{B}$ \\
\hline 1 & 0.09 & 0.46 & -0.24 & 0.51 & -0.33 & 0.06 \\
2 & 0.20 & 0.47 & -0.27 & 0.58 & -0.47 & 0.11 \\
3 & 0.21 & 0.37 & -0.26 & 0.32 & -0.47 & -0.04 \\
4 & 0.26 & 0.43 & -0.31 & 0.46 & -0.58 & 0.03 \\
5 & 0.17 & 0.37 & -0.34 & 0.47 & -0.51 & 0.10 \\
6 & 0.08 & 0.49 & -0.19 & 0.50 & -0.27 & 0.0 \\
7 & 0.17 & 0.47 & -0.22 & 0.55 & -0.38 & 0.08 \\
8 & 0.10 & 0.49 & -0.26 & 0.58 & -0.36 & 0.09 \\
9 & 0.23 & 0.51 & -0.27 & 0.63 & -0.50 & 0.12 \\
10 & 0.18 & 0.39 & -0.27 & 0.59 & -0.44 & 0.20 \\
11 & 0.06 & 0.65 & -0.19 & 0.71 & -0.25 & 0.07 \\
12 & 0.14 & 0.60 & -0.18 & 0.64 & -0.32 & 0.04 \\
13 & 0.10 & 0.72 & -0.13 & 0.64 & -0.23 & -0.08 \\
14 & 0.15 & 0.83 & -0.07 & 0.69 & -0.22 & -0.14 \\
15 & 0.11 & 0.49 & -0.07 & 0.74 & -0.18 & 0.26 \\
16 & 0.06 & 0.73 & -0.19 & 1.05 & -0.24 & 0.32 \\
17 & 0.13 & 0.61 & -0.13 & 0.82 & -0.26 & 0.21 \\
\hline & & & & & &
\end{tabular}


the fact that a grid may not just include built-up area, the observed urbanization influence obtained from the grid dataset would be diluted, compared with that obtained from the station dataset (see Fig. 3). Therefore, in the following analysis of climate change and urbanization effect, only the station dataset is used.

\subsection{Seasonal scale}

To understand seasonal variations of the temperature changes, four seasonal time series of $\mathrm{T}_{\min }$ and $\mathrm{T}_{\max }$ are studied. Figure 4 shows the seasonal trends of $T_{\min }$ and $\mathrm{T}_{\max }$ for the FDC and SDC for the two periods, 1960-1983 (Fig. 4a) and 1984-2005 (Fig. 4b), derived by using the linear least squares regression method. From Fig. 4a, it can be observed that the differences between the time series for the FDC and SDC are small, except $\mathrm{T}_{\max }$ in winter. These differences would be due to the spatial variations of the stations for the FDC and SDC, which may further corroborate the inference of no significant urbanization effect before 1984 over the study area. Moreover, Fig. 4a shows that the trends of $\mathrm{T}_{\min }$ in all seasons are larger than those of $\mathrm{T}_{\max }$, which in all seasons are negative; especially in winter

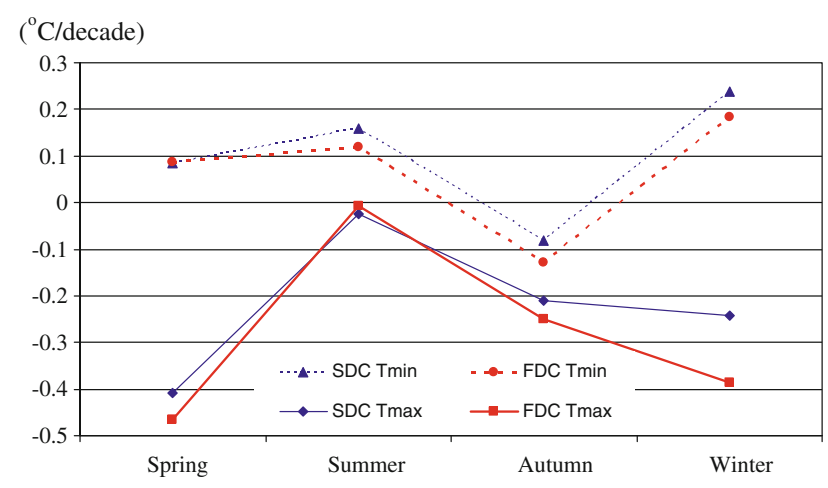

(a)

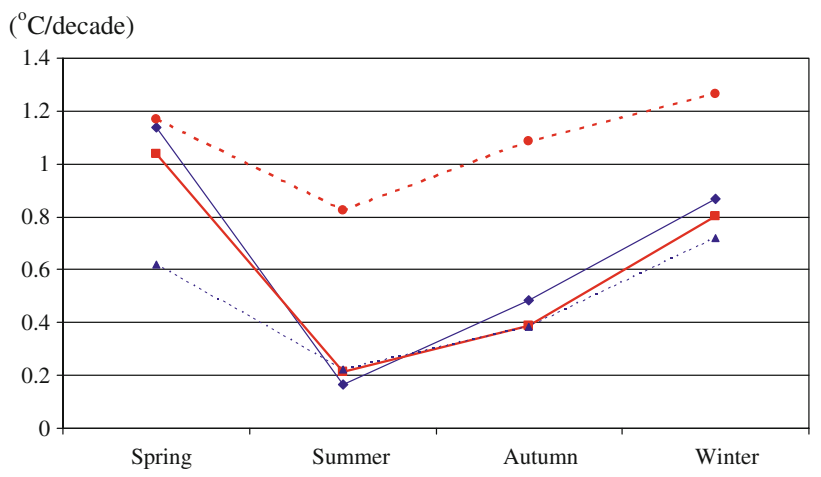

(b)

Fig. 4 Seasonal variations of the trends of $T_{\min }$ and $T_{\max }$ for FDC and SDC for the two periods, a 1960-1983, and b 1984-2005. The legends are given in $\mathbf{a}$ and spring, the trends of $\mathrm{T}_{\min }$ are larger than those of $\mathrm{T}_{\max }$ by a rate of about $0.5^{\circ} \mathrm{C} /$ decade.

For the second period (1984-2005), Fig. 4b demonstrates that all the trends of $T_{\text {min }}$ and $T_{\max }$ are positive for all the seasons and their values in winter and spring are larger than those in summer and autumn, which match with the results of Vose et al. (2005) for the northern Hemisphere. From Fig. $4 b$, it can be seen that for $\mathrm{T}_{\min }$ there is a difference of about $0.6^{\circ} \mathrm{C} /$ decade for all seasons, which is consistent with the results obtained by Tayanç and Toros (1997), while the difference in the trends of $T_{\max }$ for the FDC and SDC is trivial. In addition, for the SDC, except in summer, the trends of $\mathrm{T}_{\min }$ are smaller than those of $\mathrm{T}_{\max }$; especially in spring, the trend of $\mathrm{T}_{\max }$ is much larger than that of $\mathrm{T}_{\min }$ by about $0.5^{\circ} \mathrm{C} /$ decade, which indicates that annual DTR increase (see Fig. 3c) for the SDC is mainly due to the difference between $\mathrm{T}_{\max }$ and $\mathrm{T}_{\min }$ in spring. In contrast, for the FDC, the trends of $\mathrm{T}_{\mathrm{min}}$ are much larger than those of $\mathrm{T}_{\max }$ in summer, autumn, and winter; however, in spring there is only a slight difference (see Fig. 4b). These not only reflect the general features but also reveal the specific seasonal variations of the local urbanization influence.

Since, in the second period (1984-2005), the features of the trends of $\mathrm{T}_{\min }$ and $\mathrm{T}_{\max }$ in spring are different from those in the other three seasons and also these trends are larger in spring and winter than in summer and autumn (see Fig. $4 b$ ), these trends and the related CLs in spring and winter for $\mathrm{T}_{\min }, \mathrm{T}_{\max }$, and DTR are computed by the Senslope method and the MK test and are linearly interpolated over the region (see Fig. 5). From the first row of Fig. 5 for $\mathrm{T}_{\min }$, it can be observed that there are two centers with greatly increasing trends, which are the locations of the cities of Guangzhou and Shenzhen. However, from the middle row for $T_{\max }$, these two centers can not be identified. Furthermore, these two centers can be found from the bottom row for DTR; however, in spring, since the increasing rate of $T_{\max }$ is close to that of $T_{\min }$ for the FDC (see Fig. 4b), these two centers are not so obvious.

From the CL contours in Fig. 5, it can be seen that the CLs of all the increasing trends of $T_{\min }$ and $T_{\max }$ in spring and winter are larger than $90 \%$, and in some regions are even larger than $99 \%$. Also, for DTR, the CLs of the trends in spring are larger than $90 \%$; however, in most parts of the region, those of the trends in winter are less than $50 \%$, except in the region near the two centers (Guangzhou and Shenzhen) with CLs larger than 90\%. In addition, from Figs. 4 and 5, it can be deduced that the results gained from the linear least squares regression method are comparable to those obtained from the Sen-slope method. Moreover, it is worth noting that the CLs obtained by using the Student's $t$ test (not shown here) are consistent with those obtained by the MK test (Fig. 5). 
Fig. 5 Spatial distribution of the trends and related confidence level contours for $\mathrm{T}_{\min }$ (top row), $\mathrm{T}_{\max }$ (middle row), and DTR (bottom row) in spring (left column) and winter (right column) over the period 1984-2005
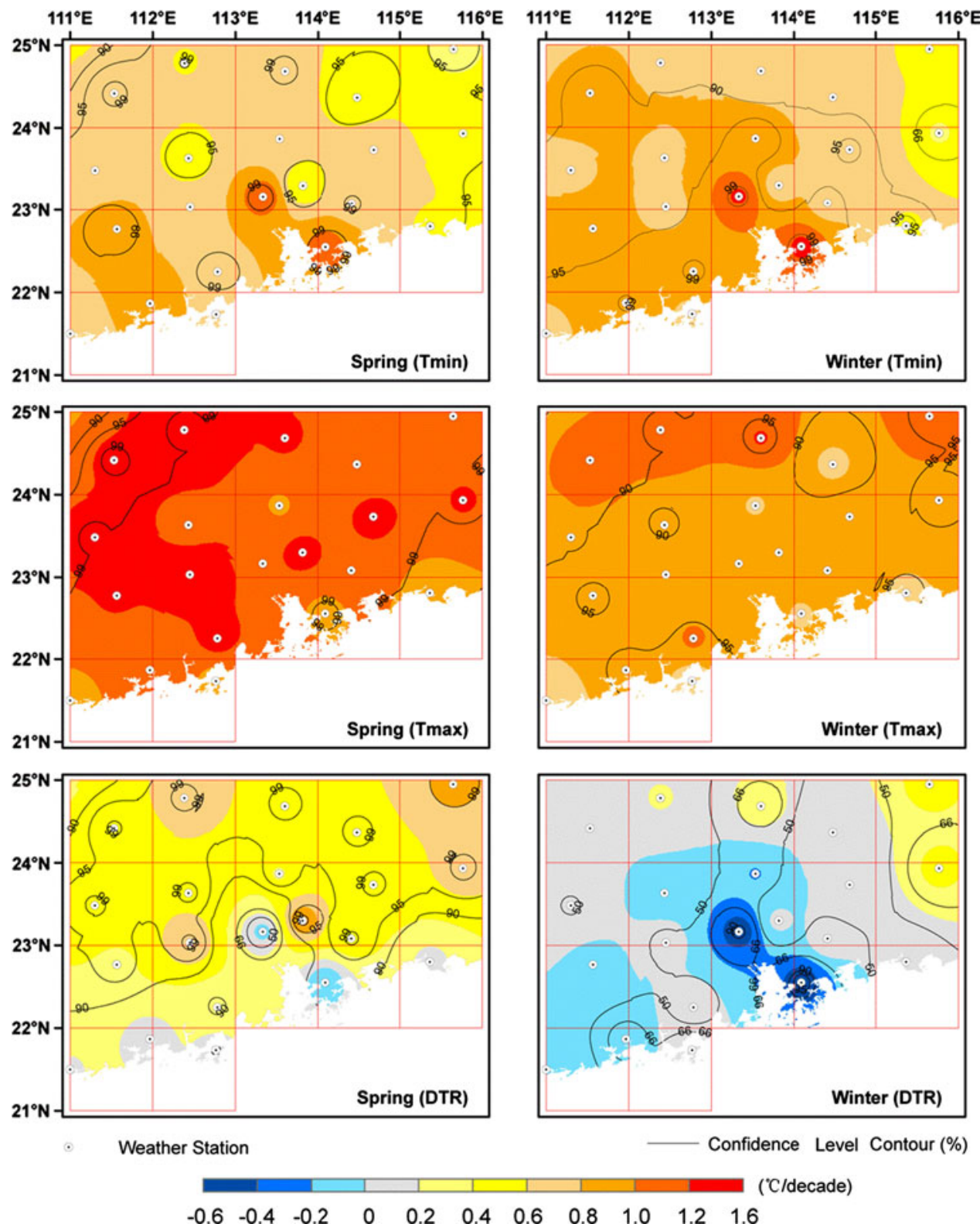

\section{RH and $P$ changes}

\subsection{Annual scale}

As in the analysis of temperature changes, the changes in RH and P are also studied for the two periods, 1960-1983 and 1984-2005, and for the FDC and SDC by using the linear least squares regression. Figure $6 \mathrm{a}$ shows that before 1984 the anomalous RH increased with a rate of $0.42 \%$ / decade and a CL of $63 \%\left(r^{2}=0.037\right)$ for the FDC and at $0.20 \% /$ decade and a CL of $36 \%\left(r^{2}=0.011\right)$ for the SDC. Figure $6 \mathrm{a}$ also reveals that after 1984 the RH decreased significantly with a rate of $-1.86 \% /$ decade and a CL of $99 \%\left(r^{2}=0.33\right)$ for the FDC and a rate of $-1.08 \% /$ decade and a CL of $97 \%\left(r^{2}=0.23\right)$ for the SDC. These features of the changes in $\mathrm{RH}$ are in agreement with those of the changes in $T_{m}$ (see Fig. 3d), since the computation of RH, as given in the following equation (see also Chow et al. (1988)) is partly dependent on $\mathrm{T}_{\mathrm{m}}$ :

$\mathrm{RH}=\exp \left(17.27 \mathrm{~T}_{\mathrm{d}} /\left(237.3+\mathrm{T}_{\mathrm{d}}\right)-17.27 \mathrm{~T}_{\mathrm{m}} /\left(237.3+\mathrm{T}_{\mathrm{m}}\right)\right)$

where $T_{d}$ is the dew-point temperature in degrees Celsius. Nevertheless, through reviewing CLs, the significance of the trends of RH is usually weaker than that of the trends of $\mathrm{T}_{\mathrm{m}}$. Furthermore, Fig. 6a reveals that the urbanization effect on RH results in an extra decrease with a rate of $0.78(=-1.86-(-1.08)) \% /$ decade.

Figure $6 \mathrm{~b}$ shows the time series of the annual anomalous $\mathrm{P}$ and related linear regression lines for the two periods, 


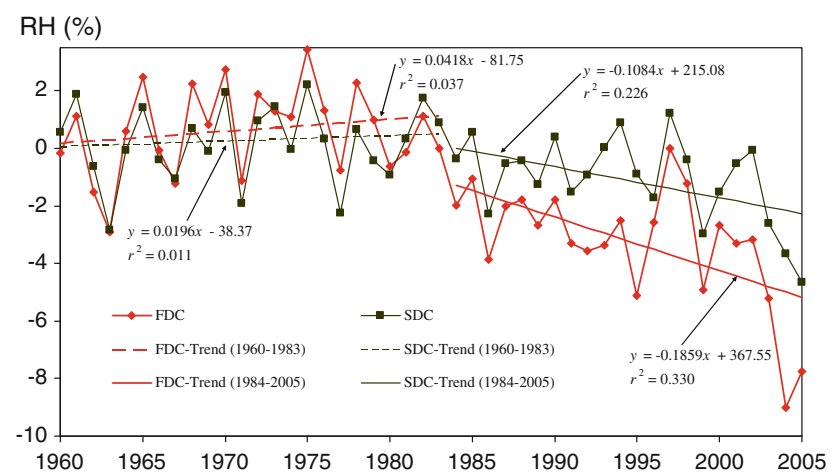

(a)

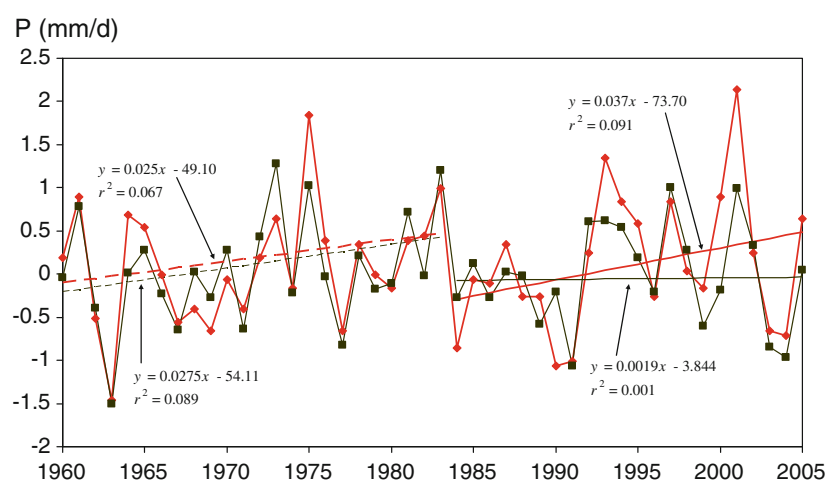

(b)

Fig. 6 Same as Fig. 3 but for RH and P

1960-1983 and 1984-2005. From the figure, it can be seen that before 1984 the trends for the FDC and SDC are similar with an increasing rate of about $96(=(0.025+$ $0.0275) / 2 \times 10 \times 365) \mathrm{mm} /$ year/decade and a CL of about $80 \%$. After 1984, the increasing trend for SDC is insignificant at about $7 \mathrm{~mm} /$ year/decade with a CL near zero, but such a trend for FDC is considerable at about $135 \mathrm{~mm} /$ year/decade with a CL of $83 \%$. The difference between the magnitude of the increasing trends for SDC and FDC suggests that the urbanization influence, which results in an increase in $\mathrm{P}$ with a considerable $\mathrm{CL}$, is observable. It is worth noting that the increasing trends over the study area for the period 1960-2005 are compatible with the results obtained by Qian and Lin (2005) and Zhang et al. (2009).

\subsection{Seasonal scale}

To further understand the changes of RH and $\mathrm{P}$, the seasonal trends over the two periods for the FDC and SDC are computed by using the linear least squares regression and are given in Table 2. From the table, it can be seen that before 1984 the trends of RH for FDC and SDC are rather similar in spring, summer, and autumn, but are different in winter, which would be due to larger decrease of $\mathrm{T}_{\max }$ for
FDC than for SDC in winter (see Fig. 4a). After 1984, the major differences of the trends of RH for FDC from those for SDC are in summer and autumn, which would be the reason behind the significant decreasing trend of the annual RH for FDC (see Fig. 6a). From Fig. 4b and Table 2, it can be inferred that the nearly-uniform increase of $T_{\min }$ in all four seasons would result in a nearly-uniform decrease of RH only in summer and autumn, which could be the seasonal features of $\mathrm{RH}$ changes due to the urbanization influence. It is worth noting that the CLs of the RH trends for FDC are about $99 \%$ in summer and $82 \%$ in autumn, but $57 \%$ and $39 \%$ for SDC, which further confirms that the urbanization effects on the RH changes are considerable.

For P, Table 2 shows that before 1984 the trends are significant with an increasing rate in spring and winter but a decreasing rate in summer for both FDC and SDC, while the trend in autumn is minor. After 1984, for both FDC and SDC, the trends are increasing in summer and autumn but decreasing in spring and winter; specifically, an increasing rate in summer for FDC is $155 \mathrm{~mm} / \mathrm{season} /$ decade with a CL of $92 \%$, and for SDC is $85.1 \mathrm{~mm} / \mathrm{season} /$ decade with a $\mathrm{CL}$ of $85 \%$, which can be inferred that the urbanization effect can result in an increase of $\mathrm{P}$ in summer with a considerable statistical significance. Table 2 also lists the seasonal average of $\mathrm{P}$, and it can be observed that the substantial increasing percentages in summer and autumn are 18.6 and $13.5 \%$ for FDC, compared with 11.8 and $2.1 \%$ for SDC, respectively, which further substantiates the urbanization influence on $\mathrm{P}$.

From Table 2, it is observed that the changes in $\mathrm{P}$ in spring and summer for the two time periods are dramatic; therefore, in order to inspect the details of the changes, the spatial distribution of the trends and related CL contours computed by using the Sen-slope method and the MK test are plotted for these two seasons and two periods (see Fig. 7). From the figure, it can be seen that the spatial variation is rather significant, and the increasing trend in spring for the first period and decreasing trend in summer for the first period and in spring for the second period are present. However, in summer for the second period (right bottom panel), the increasing trend can be found from most parts of the study area with a high CL, but the decreasing trend with a low CL is also found at the southwestern part, which reflects the spatial and seasonal variation features of climate change. Furthermore, while the urbanization influence on $\mathrm{P}$ is noticeable in Table 2, such an influence cannot intuitively be derived from the bottom row of Fig. 7. Nevertheless, comparing the top row and bottom row of Fig. 7, for both the seasons, it can be inferred that after 1984 there seems to be a region with a 'corridor shape' passing through the locations of the cities of Guangzhou and Shenzhen, which may reflect the urbanization influence on P. 
Table 2 Seasonal variation of the trends of $\mathrm{RH}$ and $\mathrm{P}$, the seasonal average of $\mathrm{P}$, and the percentage of the $\mathrm{P}$ seasonal changes for FDC and SDC over the two periods: 1960-1983 (denoted as A) and 1984-2005 (denoted as B)

Fig. 7 Same as Fig. 5 but for $\mathrm{P}$ in spring (left column) and summer (right column) for the period 1960-1983 (top row) and 1984-2005 (bottom row)

\begin{tabular}{|c|c|c|c|c|c|c|}
\hline & & & Spring & Summer & Autumn & Winter \\
\hline \multirow[t]{4}{*}{$\mathrm{RH}$ trend (\%/decade) } & \multirow[t]{2}{*}{ A } & FDC & 1.16 & -0.34 & -0.78 & 1.65 \\
\hline & & SDC & 1.13 & -0.35 & -0.66 & 0.59 \\
\hline & \multirow[t]{2}{*}{$\mathrm{B}$} & FDC & -2.69 & -1.61 & -1.6 & -0.73 \\
\hline & & SDC & -2.14 & -0.47 & -0.48 & -0.63 \\
\hline \multirow[t]{4}{*}{$\mathrm{P}$ trend $(\mathrm{mm} / \mathrm{season} /$ decade $)$} & \multirow[t]{2}{*}{ A } & FDC & 81.8 & -12.6 & -7.7 & 27.2 \\
\hline & & SDC & 112.6 & -53.9 & 0.2 & 41.4 \\
\hline & \multirow[t]{2}{*}{ B } & FDC & -19.5 & 155 & 45.4 & -9.7 \\
\hline & & SDC & -58.2 & 85.1 & 6.2 & -14.0 \\
\hline \multirow{2}{*}{\multicolumn{2}{|c|}{ P 1961-1990 average (mm/season) }} & FDC & 510.8 & 833.8 & 336.1 & 111.7 \\
\hline & & SDC & 607.1 & 722.2 & 288.4 & 146.6 \\
\hline \multirow{2}{*}{\multicolumn{2}{|c|}{$\mathrm{P}$ trend for period $\mathrm{B}$ (\%/decade) }} & FDC & -3.8 & 18.6 & 13.5 & -8.7 \\
\hline & & SDC & -9.6 & 11.8 & 2.1 & -9.5 \\
\hline
\end{tabular}
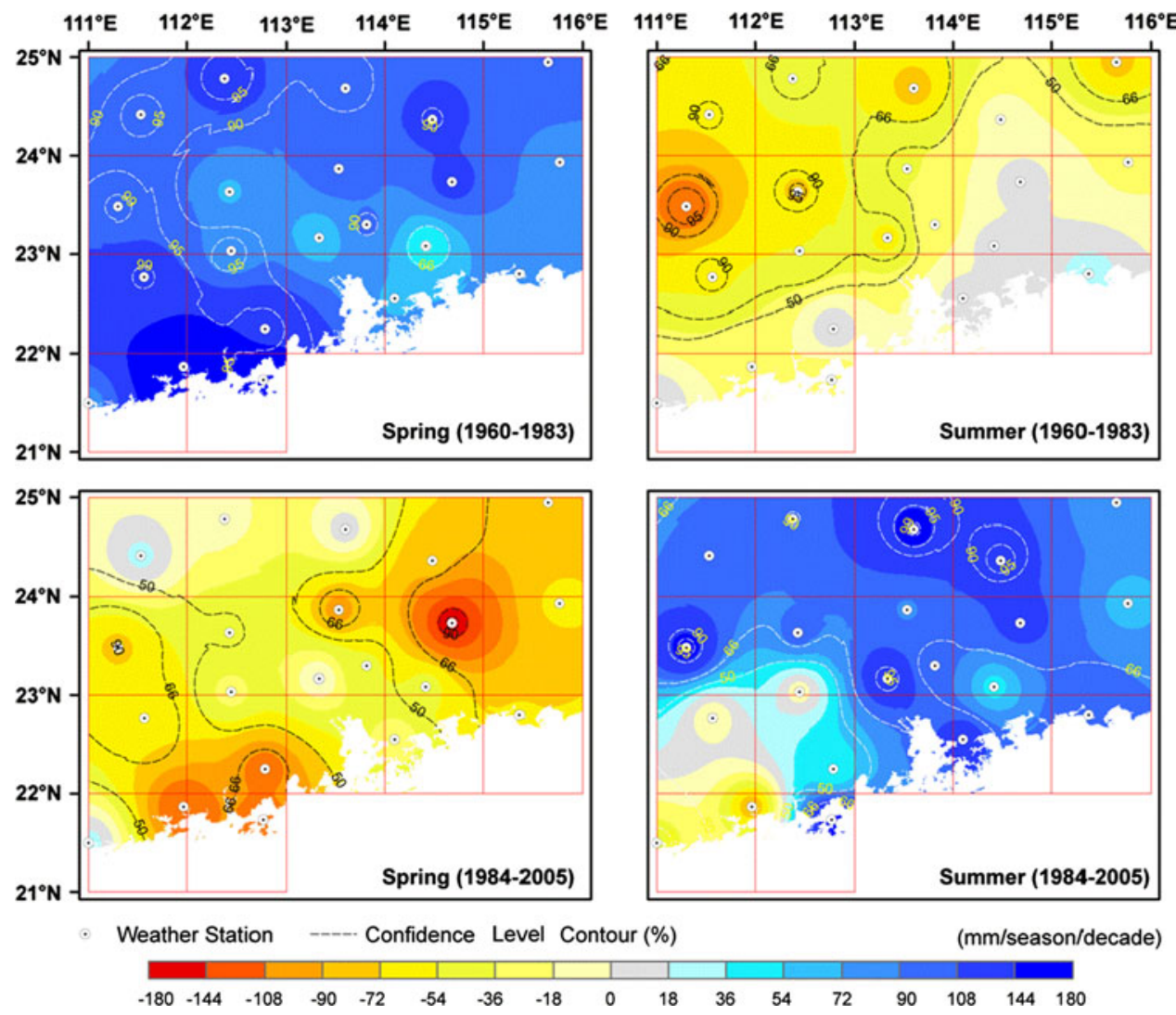

\section{Discussion and conclusions}

This paper explored the change features of and urbanization effects on the weather variables, $T_{\min }, T_{\max }$ and $T_{m}$ near surface air temperatures, DTR, RH, and P, over southeastern China. Two datasets were used in this study, one is a dataset consisting of 21 stations (mainly used) for the period 1960-2005, and the other is a grid dataset with 17 grids of a resolution of $1^{\circ} \times 1^{\circ}$ for the period 1960-2000. For the 21 stations, two categories of cities were identified, one is the FDC including Guangzhou and Shenzhen, and the other is the SDC including other 19 cities.
From the time series of the anomalous $\mathrm{T}_{\min }$ for FDC and SDC, it was observed that after 1984 the urbanization influence on climate was significant over the study area, but not before 1984. Therefore, in this study, two time periods before and after 1984 were used. Then, it was found that $T_{\min }$ increased slightly before 1984, and increased noticeably after that. In particular, an extra increasing rate of $\mathrm{T}_{\min }$ for FDC due to the urbanization influence is about 1.3 times the increasing rate for SDC. In addition, $\mathrm{T}_{\max }$ decreased before 1984 , and increased with statistical significance after that. Furthermore, this study revealed that the urbanization influence on $\mathrm{T}_{\max }$ is 
negligible. Consequently, the urbanization influence on DTR and $T_{m}$ resulted in a dramatic decreasing rate and significant increasing rate, respectively.

The RH increased slightly before 1984, but decreased considerably after 1984; especially, the urbanization influence resulted in an extra decreasing rate of $\mathrm{RH}$ for FDC after 1984. For P, before 1984, over the study area, there was an increasing rate with a low CL, and after 1984 there was a significant increasing rate for FDC but not for SDC. From a seasonal analysis, it was found that the major urbanization influence on $\mathrm{P}$ is in summer.

It is worth noting that the phrase 'slow developing cities' instead of 'rural areas' is used in this study. With the investigation of the population and built-up area over FDC and some cities of SDC, it can be inferred that the weather observations from SDC are equivalent to those from rural areas before 1984; however after 1984, those observations from SDC would include little urbanization influence. A careful study with the observations from more weather stations over the study area should be undertaken. Nevertheless, the results presented in this paper would be valuable to enhance our understanding of the climate change and urbanization effects, and provide a basis for further investigations.

Acknowledgements This research was supported by the Hong Kong RGC GRF project (HKU 7117/06E), and PPR project (HKU 7022-PPR-2). The authors are grateful for the valuable review comments and suggestions from the two anonymous reviewers. Also, the authors thank the guest editor of this special issue, Bellie Sivakumar, for his invaluable work of editing our paper.

Open Access This article is distributed under the terms of the Creative Commons Attribution Noncommercial License which permits any noncommercial use, distribution, and reproduction in any medium, provided the original author(s) and source are credited.

\section{References}

Bates BC, Kundzewicz ZW, Wu S, Palutikof JP (2008) Climate change and water. Technical Paper of the International Panel on Climate Change, IPCC Secretariat, Geneva, p 210

Becker S, Gemmer M, Jiang T (2006) Spatiotemporal analysis of precipitation trends in the Yangtze River catchment. Stoch Environ Res Risk Assess 20:435-444

Chen J, Kumar P (2002) Role of terrestrial hydrologic memory in modulating ENSO impacts in North America. J Clim 15:3569-3585

Chow VT, Maidment DR, Mays LW (1988) Applied Hydrology. McGraw-Hill, Inc., New York

Feng S, Hu Q, Qian W (2004) Quality control of daily meteorological data in China 1951-2000: a new dataset. Int J Climatol 24:853-870

Gachon P, St. Hilaire A, Ouarda T, Nguyen VTV, Lin C, Milton J, Chaumont D, Goldstein J, Hessami M, Nguyen TD, Selva F, Nadeau M, Roy P, Parishkura D, Major N, Choux M, Bourque A (2005) A first evaluation of the strength and weaknesses of statistical downscaling methods for simulating extremes over various regions of eastern Canada. Sub-component, Climate Change Action Fund (CCAF), Environment Canada, Final report, Montréal, Québec, Canada, 209 pp

Guangdong Statistic Bureau (2006). Guangdong Statistical Yearbook. China Statistic Press, 663 pp

Hamburg M (1970) Statistical analysis for decision marking. Brace \& World Inc., Harcourt, p 817

Hansen J, Sato M, Ruedy R, Lo K, Lea DW, Medina-Elizade M (2006) Global temperature change. Proc Natl Acad Sci USA 103(39):14288-14293

Higgins RW, Janowiak JE, Yao Y (1996) A gridded hourly precipitation database for the United States (1963-1993). NCEP/CPC Atlas, No 1

IPCC (2007) Climate Change 2007: Synthesis Report. Contribution of working group I, II and III to the fourth assessment report of the intergovernmental panel on climate change. [Core Writing Team, Pachauri RK, Reisinger A (eds)], IPCC, Geneva, Switzerland, $104 \mathrm{pp}$

Jones PD, New M, Parker DE, Martin S, Rigor IG (1999) Surface air temperature and its variations over the last 150 years. Rev Geophys 37:173-199

Kalnay E, Cai M (2003) Impact of urbanization and land-use change on climate. Nature 423:528-531

Kendall MG (1975) Rank correlation methods. A Charles Griffin Book, London

Leung YK, Yeung HK, Ginn WEL, Leung WM (2004) Climate change in Hong Kong. Hong Kong Observatory Technical Note No. $107,48 \mathrm{pp}$

Li Q, Zhang H, Liu X, Huang J (2004) Urban heat island effect on annual mean temperature during the last 50 years in China. Theor Appl Climatol 79:165-174

Li Q, Zhang H, Chen J, Li W, Liu X, Jones P (2009) A mainland China homogenized historical temperature dataset of 1951-2004. Bull Am Meteorol Soc 90(8):1062-1065. doi:10.1175/2009BAMS2736.1

Mann HB (1945) Nonparametric tests against trend. Econometrica $13: 245-259$

Qian W, Lin X (2005) Regional trends in recent precipitation indices in China. Meteorol Atmos Phys 90:193-207

Qian W, Zhu Y (2001) Climate change in China from 1880 to 1998 and its impact on the environmental condition. Clim Change 50:419-444

Ren G, Zhou Y, Chu Z, Zhou J, Zhang A, Guo J, Liu X (2008) Urbanization effects on observed surface air temperature trends in North China. J Clim 21:1333-1348

Sen PK (1968) Estimates of the regression coefficient based on Kendall's Tau. J Am Stat Assoc 63(324):1379-1389

Tayanç M, Toros H (1997) Urbanization effects on regional climate change in the case of four large cities of Turkey. Clim Change 35:501-524

Vose RS, Easterling DR, Gleason B (2005) Maximum and minimum temperature trends for the globe: an update through 2004. Geophys Res Lett 32:L23822. doi:10.1029/2005GL024379

Weng Q (2001) A remote sensing-GIS evaluation of urban expansion and its impact on surface temperature in the Zhujiang Delta, China. Int J Remote Sens 22(10):1999-2014

Willett KM, Jones PD, Gillett NP, Thorne PW (2008) Recent changes in surface humidity: development of the HadCRUH dataset. J Clim 21:5364-5383

Zhang Q, Xu CY, Zhang Z, Chen YD, Liu CL (2009) Spatial and temporal variability of precipitation over China, 1951-2005. Theor Appl Climatol 95:53-68

Zhou L, Dickinson RE, Tian Y, Fang J, Li Q, Kaufmann RK, Tucker CJ, Myneni RB (2004) Evidence for a significant urbanization effect on climate in China. Proc Natl Acad Sci USA 101(26):9540-9544 